\title{
The Potential Problem for Mechanical Applications and Solutions
}

\author{
Caifang Zhang \\ Chongqing Vocational Institute of Engineering, Chongqing, 400037,China
}

\author{
Keywords: Mechanical application. Technical problems. Countermeasures
}

\begin{abstract}
The machinery industry is an important part of our industry, and mechanical use range is wide, large market demand, which has a great influence on the development of other industries. For mechanical applications, the potential problems have been unable to resolve, resulting in a difficult market expanding. In addition, to grasp the core technology, mechanical industrial production technology is still unable to reach the level of demand. This article through the analysis of potential technical problems existing in the machinery industry, and explore the solving measures, so as to strengthen the R\&D of core technology, improve production efficiency.
\end{abstract}

\section{Introduction}

With the material conditions of our citizens and the quality of spiritual life changes and advances in science and technology, and promote the development speed of mechanical engineering applications, and plays an outstanding contribution to society in various fields, such as medical, aerospace, vehicles, machinery and equipment, electronics significant areas of industries. Through constant innovation and progress ,in all aspects of social life mechanical act as an important role. Mechanical application of technology is not only a direct reflection of the level of a country's machinery related industries the pace, still the main way to ensure rapid growth in the manufacturing sectors of the national economy.

\section{Analysis of potential technical problems}

In order to accelerate the implementation of our party proposed implementation on the construction of a comprehensive well-off society goals, and in the next 7 years, gross domestic product (GDP) grand target based on 2000 in GDP quadrupling, solve the technical problems of potential industry of machinery of our country project urgently needed. But when we explore the solution to the whole construction machinery industry and the development of their own have a clear, comprehensive and objective understanding. Countermeasures conducted by analysis of various products, technologies, personnel and industrial structure, integrated various factors, thereby seeking to fit their business and industry to improve the way forward direction.

\section{Poor product quality and product type single potential crisis}

For the product itself, we should improve the quality and increase the diversity at the start. Although China's economy since the policy of reform and open markets to insist for a long time for the import of technology and resources, implement the international ISO quality management system standard. However, the domestic machinery products in terms of quality still exists a wide gap compared with developed industrial countries of the world. Many consumer businesses and individuals in the survey said the domestic machinery products, there are many problems in life, reliability, economic efficiency, energy saving and environmental protection targets, which makes domestic products in the sales and marketing areas are not consistent with the foreign advanced products ratio.

In addition , the domestic market is uncompetitive caused by the unity of their products , and it is difficult to adapt to changing market demand and market competition. Narrow range of product unity determines the survival of enterprises in the increasingly fierce competition in the international market, product category, backward technology company has been gradually merger and acquisition by large group. Large international companies are with many kinds of products, fully functional , 
even in a commanding position in the product areas . Although China's construction machinery industry in the number of enterprises, but mostly small scale, product range is too simple, and there is no large-scale production, so build brands, improve the status of the enterprise pose is a real problem . Therefore, you need to identify the market position, from a market perspective, to ensure that their production output and direction are correct. Furthermore, in terms of production technology for machinery , but also identify the direction, can not appear inferior production problems. Currently , high-tech emerging, in many ways have a larger impact. For mechanical production, the introduction of high-tech should be able to achieve a breakthrough in the technology of production, in order to achieve efficient production machinery .

\section{For less mastered the core technology and applications}

The rapid development of China's machinery and application technology for many years, product manufacturing industry has achieved a certain status and achievement in the world scope and level,and in the international market it has become a big country of manufacture.But in the technology, especially in the master the core technology of high end products, compared with the international advanced level there are obvious gaps. In addition, the technological level of China's engineering machinery is also affected by the domestic economic development constraints. Especially in the premise of the development of global economic integration, many enterprises are restricted to the survival and development of the core technology, not self-developed products or not mastered the core technology of the main components, can only rely on imports of key parts. Besides, the independent research and development ability is not high, and the lack of innovation in the mechanical application of performance, quality, varieties, the products are lack of effective application of competitiveness at home and abroad. The core technology, is a necessary factor to determine the long-term development of the machinery industry. If the lack of core technology available, it will gradually lack of market, eventually lose their market competitiveness.

Slow adjustment of industrial structure is not conducive to the development of the industry

The adjustment of industrial structure should include the whole machinery industry structure and product structure adjustment in two aspects. After China's reform and opening up, construction machinery industry has made considerable progress. Rapidly increasing number of industrial enterprises in machinery mushroomed. However, due to the pursuit of machinery all over the region's industrial system development, business planning and therefore fragmented, concentration is too low, can not form a large-scale production, so that the adverse long-term development of enterprises. International construction machinery industry developed rapidly in the multinational, the scale is also growing, worldwide sales network, through the advantages of core technology competitiveness, greatly improving the international competitiveness. In a tough market situation, if not the entire industry restructuring, which is jointly through mutual and closed, the formation of other means to expand their market share and strength, it is difficult to compete with other multinationals.

Industrial restructuring, while according to the domestic market demand and combined with the international market competition changes, product strategy adjustment to give priority to the development of competitiveness significantly, which is already achieved some competitive products, the original species on the basis of innovation adding new varieties to meet the diverse needs of product features. From the current market demand analysis, the ultra-compact, miniature engineering machinery, multi-operating mechanical devices, unmanned remote control energy saving machinery and construction machinery more and more consumers. Also in product development, design stage, do market research and analysis, according to the actual situation in the country areas, meet under different climate conditions in different regions, and in the pursuit of international technical standards at the same time pay more attention to the needs of domestic market.

\section{Development strategy of mechanical applications and Solutions}

\section{Improve overall application quality and diversity}

To improve the overall quality of products from many aspects, including improving parts quality, product standards, the overall quality, production and management personnel of the strict 
implementation of process and test quality adjustment link index, enhance their overall quality concept. The quality is the fundamental solution to enhance the competitiveness of enterprises. Now our country's economic development has close to global integration, engineering machinery increasingly to internationalization, especially for China accession to the WTO, the more the introduction of international advanced technology and excellent resources configuration provides a good opportunity, Ii is believed that in not the long time, the quality of our products and technologies of mechanical application would be better to improve.

Product range from unity to diversify is constantly adapt to the requirements put forward by the mechanical application market. Product diversification reflects the mechanical application of the ability to respond to market changes. And whether it is diversified product features, or both diverse applications for business survival and development to provide a guarantee, in expanding the domestic market and even make a solid foundation to build on international brands.

Pay attention to personnel training and enhance the capability of independent innovation

Modern enterprise competition in the final analysis is the high-tech talent contest,.Technical knowledge within the enterprise personnel directly affects the future development direction and the pace of development of the enterprise.Without high technology talents in the enterprise, will be very difficult to have new breakthrough. It can only rest on its laurels, impossible in the market with large group enterprises to match, so, efficient way of high-tech personnel training and re-education concern is to improve their competitiveness. International construction machinery industry in the rapid development, advanced product concept and manufacturing technology constantly launch. Only the high technical personnel as the company's "organ" of digestion and absorption of these knowledge, and use the power converted to promote business growth. Therefore, to the enterprise long-term survival and development, we must work hard to introduce and train a group of professional ability of high-quality technology development personnel, absorption of foreign advanced technologies in the digestion, combined with the actual needs of the domestic market, research and development of new products, and strive to core technology with independent intellectual property rights, so that enterprises to introduce changes in domestic independent innovation from dependence on foreign, so that not only get rid of the dependence of foreign key technologies and main components, and to reduce product cost, improve service level and enhance corporate visibility to add speed.

\section{Actively promote the adjustment of industrial structure, and promote the industry leading large enterprises}

Practice has proved that with strong international competitiveness of enterprises are large enterprises, large corporations. In the development of China's construction machinery industry, realize the industrial modernization goal, to healthily and fast set up some large enterprise groups through enterprise reform, reorganization and merger, with world-renowned enterprises struggling at the same stage in the construction machinery industry . In the choice of $M$ \& A enterprises, combining the research of its own, carefully consider the change of restructuring after M\&A, preferred enterprises with funds, technology, management, market.Through the application of structural adjustment, so that the whole industry have emerged a number of the leading role of large enterprises. To these enterprises as the center, actively support and nurture collaboration specialization of production supporting small enterprises, to the surrounding fragmented industry to scale, and gradually formed a clear division of labor in application system. The whole construction machinery industry occupies a certain position in the world, for Chinese enterprises to provide a favorable business environment conditions in the international competition.

Therefore, China's construction machinery industry, we must seize every good opportunity. According to the market situation changes, and actively promote their own product structure adjustment; pay enough attention on talent introduction and training; through ongoing research experiments repeatedly adjust the design of new products, the formation of independent master the core technology to enable enterprises to operate in the follow-up capable of implementing the "big company strategy" stronger. And ultimately the business scale, product quality grade, advanced manufacturing technology, service level of class, to win one of the world on the international market. 


\section{Conclusion}

At present, many enterprises in China construction machinery industry have the ability to enter the international market.But to get the advantage in the international competition, there are many problems to be solved, such as scientific information and network technology, the enterprises in the construction of the marketing management system establishment, product sales network and marketing team to consolidate stability etc.No matter which side is not ready and stronger, enterprises in the competition will eventually be eliminated. Therefore, for the machinery production enterprises, the potential problems of mechanical production and use to pay close attention to, and be able to identify the problems, provide solutions, thereby lifting machinery manufacturing enterprises in the same industry competitiveness.

\section{References}

[1] Li Shikun, Zhao Hui: Using PLC to transform the A-6130-100t multi station automatic control system for press, Harbin Bearing, 2009 (3):29-30

[2] Zhang Yong, Hu Jingming, Li Hang, Gao Weiliang, Su Lin Chengyang: A tubular heat exchanger structure based on CFD technology improvements, Journal of Hunan University of Technology, 2012 (4): $97-100$

[3] He Peng, Wang Zhen: Numerical simulation of reinforcement in a coal mine in Huainan mining area, Journal of North China Institute of Water Conservancy and Hydropower, 2012 (5): 91-94 